\title{
ANTROPOCENO PATRIARCAL, PETRO-MASCULINIDADES E MASCULINIDADES INDUSTRIAIS: DIÁLOGOS FEMINISTAS SOBRE A CRISE CLIMÁTICA

\section{Resumo}

Este artigo analisa criticamente a forma como as elites políticas masculinas da ultradireita persistem em negar as alterações climáticas, uma estratégia político-discursiva de preservação do status quo, do qual sempre beneficiaram. Servindo-se dos conceitos de "petro-masculinidade», de «masculinidades industriais» e introduzindo o conceito de «Antropoceno patriarcal», este trabalho argumenta que o negacionismo climático destes líderes políticos está inextricavelmente ligado às suas identidades masculinas. Neste sentido, estes discursos contribuem para (re)produzir masculinidades autoritárias e ecologicamente irresponsáveis.

Palavras-chave: Crise climática, Antropoceno, masculinidades, ultradireita.

\section{Abstract \\ Feminist Dialogues on the Climate Crisis: Patriarchal Anthropocene, Petro-masculinities and Industrial Masculinities \\ This article critically analyzes how far-right political male elites persistently deny climate change, a political-discursive strategy of maintaining the status quo, which has historically benefited them. Making use of concepts such as "petro-masculinity» and «industrial masculinities», and introducing the concept of «patriarchal Anthropocene», this paper argues that climate denial is inextricably linked to these leaders' masculine identities. Thus, these discourses contribute to the (re)production of authoritarian and ecologically irresponsible masculinities.}

Keywords: Climate crisis, Anthropocene, masculinities, far right.

Investigadora Júnior no Centro de Estudos Sociais da Universidade de Coimbra (CES/UC), 3000-104 Coimbra, Portugal.

Endereço postal: Centro de Estudos Sociais, Colégio de São Jerónimo, 3000-104 Coimbra, Portugal. Endereço eletrónico: mariana.riquito@gmail.com / marianariquito@ces.uc.pt 


\begin{abstract}
Résumé
Dialogues féministes sur la crise climatique: Anthropocène patriarchal, petromasculinités et masculinités industrielles

Cet article analyse de manière critique comment les élites politiques masculines d'extrême-droite nient de façon persistante le changement climatique, une stratégie politicodiscursive de préservation du statu quo dont elles ont toujours bénéficié. En utilisant les concepts de "pétro-masculinité», de «masculinités industrielles» et en introduisant le concept d' "Anthropocène Patriarcal», cet article considère que le négationnisme climatique de ces dirigeants est inextricablement lié à leurs identités masculines. En ce sens, leurs discours contribuent à la (ré)production de masculinités autoritaires et écologiquement irresponsables.
\end{abstract}

Mots-clé: Crise climatique, Anthropocène, masculinités, extrême-droite.

\title{
Introdução
}

Nos últimos anos, assistimos à eleição de vários chefes de Estado da ultradireita, na sua maioria homens, cujos discursos, valores e projetos políticos parecem ter ressuscitado alguns fantasmas do passado. É o caso de Donald Trump nos Estados Unidos da América (EUA), de Jair Messias Bolsonaro no Brasil, de Narendra Modi na Índia, de Rodrigo Duterte nas Filipinas, de Viktor Orbán na Hungria, entre outros. Muito embora as trajetórias, as intenções e as retóricas destas lideranças políticas sejam sempre únicas e específicas aos seus contextos locais, há elementos comuns entre elas (Mudde 2019). Todas elas promovem uma visão autoritária da sociedade (Wodak 2015; Mudde 2019), um projeto político que adere à lógica económica neoliberal (Halimi e Rimbert 2019; Dardot e Laval 2019), tendem a ser céticas, ou até mesmo negacionistas, quanto ao impacto das atividades humanas sobre os sistemas climáticos (Pulé e Hultman 2019a e 2019b; Forchtner 2020), e fazem uso de uma retórica assente numa ideia monolítica, exclusivista e identitária do «povo» (Wodak 2015; Mudde 2019).

A par do avanço da ultradireita, os movimentos emancipatórios por justiça social global ganharam um novo fôlego (Bringel e Pleyers 2017). Tanto a luta feminista como a luta ambientalista têm vindo a adquirir expressão mediática, pública e política muito significativa (Arruzza, Bhattacharya e Fraser 2019; Pellizzoni 2019). As lutas ambientalistas, no seu combate contra o antropocentrismo e contra a exploração do meio ambiente, e as lutas feministas, no seu combate contra o patriarcado e contra a exploração das mulheres e outras minorias sociais, constituem agendas eminentemente emancipatórias, pois o seu intuito é romper com as estruturas de dominação vigentes: o patriarcado, o antropocentrismo, o racismo, o (neo)colonialismo. A ultradireita contemporânea, pelo contrário, representa a vontade de manter uma sociedade estritamente ordenada, autoritária, reacionária e repressiva (Giddens 2007; Bello 2019; Mudde 2019). 
É neste sentido que as pautas progressistas surgem como ameaças nos discursos destes líderes (Wodak 2015; Mudde 2019; Norris e Inglehart 2019). Historicamente, esta dinâmica é muito comum: sempre que houve movimentos de grande agitação social, os membros da maioria exprimem um «ressentimento profundo», nos termos de Elias (1991), ou, nas palavras de Appadurai (2009), uma «ansiedade da incompletude», isto é, temem a perda de privilégios, de poder e de controlo. Ao sentirem que o seu estatuto se encontra ameaçado pelas propostas emancipatórias, procuram invisibilizar, menosprezar ou violentar quem luta por transformação social.

No contexto atual de crise ecológica, os discursos negacionistas climáticos proferidos pelos líderes da ultradireita seguem essa mesma lógica. Muito embora tenhamos evidências científicas avassaladoras quanto à relação de causa-consequência entre o extrativismo/industrialização e as alterações climáticas, e tenhamos inclusive atingido consensos políticos globais ${ }^{1}$ de modo a reduzir - ou mesmo acabar com - a queima e extração de combustíveis fósseis, estes líderes políticos da ultradireita descredibilizam propositadamente a ciência e negam as alterações climáticas antropogénicas (Forchtner 2020). Fazem-no pois são dos principais beneficiários da ordem industrial moderna, pelo que as medidas de mitigação climática e de descarbonização ameaçam o seu estatuto político-económico dominante (Anshelm e Hultman 2014; Daggett 2018; Pulé e Hultman 2019b). Ora, a ordem industrial moderna, extrativista, produtivista e fóssil foi historicamente sustentada, legitimada e perpetuada pela ordem patriarcal branca (ibid.). A crise ecológica que enfrentamos está, pois, profundamente relacionada com as estruturas generificadas em que assentam as práticas, as identidades sociais e as relações sociais de poder. Isto é, as alterações climáticas são atravessadas, em permanência, pelas estruturas de opressão patriarcal e por isso mesmo devemos entender as alterações climáticas como uma problemática feminista (ibid.).

Assim, no contexto dos discursos proferidos pelas lideranças masculinas da ultradireita no tocante às alterações climáticas, é importante reconhecer e explorar de que modo são perpetuados padrões hegemónicos de masculinidade que reforçam os tradicionais estereótipos de género e contribuem para comportamentos ecologicamente irresponsáveis e devastadoras. Ao negarem as causas antropogénicas das alterações climáticas e ao considerarem como ameaças as lutas sociopolíticas feministas, os líderes políticos da ultradireita dificultam todos os esforços coletivos de mitigação das alterações climáticas e tendem a restringir e a retroceder em direitos para minorias. Neste sentido, a retórica empregue pela ultradireita tem vindo a acentuar - e até mesmo a agravar - as diferentes crises que atravessamos: política, económica, social, institucional e ambiental.

Perante estas diferentes crises, parece-nos crucial estudar de que forma certos chefes de Estado, face à urgência climática, persistem em negar ou, pelo menos,

É o caso do Acordo de Paris ou do Pacto Ecológico Europeu, para citar apenas os mais recentes. 
em diminuir o problema, atacando simultaneamente e de forma co-constitutiva as agendas e as agentes feministas. Neste artigo, propomo-nos perceber de que forma os líderes políticos da ultradireita reagem à crise climática (re)produzindo padrões de masculinidade que protegem a ordem vigente.

Para responder a esta problemática, o artigo colhe das epistemologias feministas, apoiando-se nomeadamente no ecofeminismo, e dos estudos sobre masculinidades, mobilizando conceitos como «petro-masculinidades» e «masculinidades industriais». $\mathrm{O}$ artigo está dividido em três secções diferentes. Na primeira, discorremos sobre os fundamentos teórico-epistemológicos do ecofeminismo, que guiarão a nossa análise; na segunda, tecemos uma leitura (eco)feminista da crise climática; na terceira, avaliamos a posição dos líderes da ultradireita face à crise climática, explorando que masculinidades são (re)produzidas, ilustrando esta hipótese com exemplos concretos.

\section{A teoria ecofeminista: interseccionalidade(s) entre a dominação patriarcal e a exploração da Natureza}

A teoria ecofeminista considera que as estruturas do "patriarcado» e as estruturas do antropocentrismo se reforçam mutuamente através das estruturas do sistema capitalista global e operam segundo uma lógica comum, oriunda do pensamento ocidental moderno. Esta imbricação dos diferentes sistemas opressivos deu origem ao que Mies e Shiva (2014) apelidam de patriarcado capitalista - um sistema global de opressão generizada em prol do lucro, do crescimento económico e da lógica do mercado, que acentua, por um lado, a dominação patriarcal e, por outro lado, a exploração da Natureza.

Definimos «patriarcado» como o sistema de estruturas e de práticas sociais nas quais os homens dominam, oprimem e exploram as mulheres (Walby 1989) e os homens cujas opções, identidades e comportamentos não são consentâneos com o que se convencionalmente se consensualizou como sendo «masculino» (Connell 1993). Isto porque, no quadro das sociedades patriarcais, o «género masculino» - e as práticas, valores e identidades a ele associadas - encontra-se, de forma sistemática, em posição de poder. Assim, falar de «masculinidade» implica falar de poder, pois este termo refere-se ao conjunto de padrões comportamentais e de práticas identitárias através das quais os homens e as mulheres atingem e perpetuam uma determinada posição social, política e económica de poder (ibid.). Embora nem todos os homens tenham vocação para a dominação, todos os homens sofrem uma pressão para almejarem uma prática hegemónica da masculinidade. A «masculinidade hegemónica» é normativa: ela simboliza a forma mais honrosa de se ser homem, é uma masculinidade construída em relação e por oposição às mulheres e às outras masculinidades, pelo que ela é simultaneamente definidora do que significa «ser-se homem» e excludente de todas as pessoas que nela não se enquadrem (ibid.). 
Historicamente, o sistema patriarcal foi legitimado por uma conceção androcêntrica do mundo, isto é, uma visão filosófica centrada em perspetivas, padrões e valores masculinos (Hibbs 2014). Esta conceção filosófica tem vindo a justificar a exploração do Homem sobre a Natureza, legitimando práticas violentas sistémicas - a que apelidamos de «antropocentrismo» (Gaard 1993; Boddice 2011; Mies e Shiva 2014; Solón 2019). O antropocentrismo encontra legitimidade filosófica no pensamento ocidental moderno, um pensamento abissal, criador de «divisões visíveis e invisíveis» (Santos 2007, 71), que estrutura o mundo em binarismos dicotómicos: Homem/Natureza, espírito/corpo, bom/mau, civilizado/selvagem, razão/ emoção, cultura/saberes ancestrais, independência/dependência (Santos 2007; Mies e Shiva 2014). Estes binarismos são entendidos como «pares de contrários com valor desigual» (Herrero e Pascual 2010, 1): «Homem», por exemplo, é entendido como «superior» à «Natureza». Este pensamento dicotómico-hierárquico serve de princípio justificativo e legitimador das relações de opressão: apenas compreendendo o «Homem» como «superior» à «Natureza» é legítimo que este domine a primeira; de forma semelhante, apenas a compreensão do «homem» como «superior» à «mulher» permite a subjugação desta última.

Segundo as teorias (eco)feministas, estes binómios fundadores do pensamento ocidental moderno são profundamente generificados. Isto é, esses pares estão associados e são atribuídos a cada um dos géneros, também eles concebidos de forma binária. De um lado, o masculino, entendido como superior, próximo da cultura e da razão; de um outro, o feminino, percecionado como inferior, essencialmente ligado à Natureza e submetido às emoções. A primazia do masculino legitimou que o domínio do mundo físico tenha sido protagonizado pelos homens, enquanto as mulheres, pelo contrário, foram associadas ao mundo instável das emoções e relegadas à esfera doméstica (Gaard 1993; Herrero 2013; Mies e Shiva 2014; Fraser 2017; Federici 2019).

É esta análise que permite à teoria ecofeminista analisar conjuntamente as estruturas de exploração da Natureza e as estruturas de opressão patriarcais, que o capitalismo global tem vindo a exacerbar. Por um lado, o capitalismo acentuou as estruturas patriarcais ao invisibilizar, desqualificar e desvalorizar o trabalho reprodutivo e de cuidado que as mulheres exercem em espaços (ainda) não mercantilizados (ibid.). Por outro lado, o capitalismo reforçou a visão antropocêntrica do mundo, segundo a qual a Natureza é passível de ser explorada, dizimada e transformada em prol do lucro, pois esta conceção serviu de base ideológica e legitimadora dos processos de industrialização, de tecnologização, de extração de recursos e de acumulação de capital, nomeadamente no Sul Global (Gaard 1993; Herrero 2013; Mies e Shiva 2014; Bello 2019; Solón 2019).

Com efeito, desde a Revolução Industrial - marco do início definitivo do capitalismo (Foster 1977; Grassby 1999) - que os progressos científico-tecnológicos têm determinado a necessidade de se ultrapassar os limites da Natureza para criar 
abundância económica. A rationale capitalista do crescimento ilimitado sugere que podemos violar e destruir a Natureza, da qual nós fazemos parte, sem sofrer os efeitos desse esgotamento, pelo que este modelo baseado na exploração infinita dos recursos naturais é fundamentalmente anti-ecológico (Paterson 2005). Para além da degradação ecológica, este modelo económico gerou novas formas de opressão patriarcal, tendo separado, de forma profundamente generizada, a reprodução social da produção económica (Fraser 2017): o objetivo do crescimento ilimitado apenas pôde ser sustentado porque as mulheres sistematicamente exercem um papel de género específico - a procriação, o cuidado e as tarefas domésticas -, economicamente não remunerado e socialmente não valorizado (ibid.).

A teoria ecofeminista questiona, pois, os fundamentos do atual modelo civilizacional, que depende da espoliação da Natureza e da exploração das mulheres, e que deu origem aos níveis irreversíveis de degradação socioecológica a que assistimos.

\section{Uma leitura ecofeminista do Antropoceno: crise climática, género, raça e classe}

Perante a rápida e profunda degradação ecológica que experienciamos e constatando a inseparabilidade entre as atividades humanas e os sistemas climáticos, Crutzen e Stroemer (2000) propuseram o termo «Antropoceno» - que significa literalmente a «Era dos Humanos» - para definir o período geológico mais recente da Terra. Ora, a utilização desse conceito reforça a ideia segundo a qual toda a Humanidade é responsável, de igual modo, pela destruição da Natureza e, como bem demonstra a teoria ecofeminista, a imagem de uma Humanidade homogénea é contrariada em permanência pelas gritantes assimetrias de poder.

Em 2017, apenas oito pessoas - oito homens, por sinal - possuíam a mesma riqueza que 3,6 biliões de pessoas, a metade mais pobre da humanidade (OXFAM 2017). Entre 1988 e 2017, 71\% das emissões globais de CO2 foram causadas por somente 100 empresas (Climate Accountability Institute 2017). Em 2015, os 10\% mais ricos do mundo produziam metade dessas emissões globais, enquanto a metade mais pobre contribuía apenas em 10\% (OXFAM 2015). Em 2014, de entre 29 cientistas, apenas uma mulher fazia parte do grupo de trabalho berlinense sobre o Antropoceno, e apenas quatro membros provinham do Sul Global (Raworth 2014). Estes números demonstram que são as grandes empresas e multinacionais do Norte Global que geram - através das suas atividades económicas extrativistas - impactos irreversíveis e de grande escala nos sistemas climáticos. Também são ilustrativos de como as mulheres e as pessoas do Sul Global são sistematicamente silenciadas e retiradas das estruturas de decisão internacionais. Em suma, estes exemplos demonstram que não é possível analisar os contornos do fenómeno «Antropoceno» se não procurarmos relacioná-los com as relações de poder. 
É nesse sentido que termos como «Capitaloceno» (Moore 2016), «Plutoceno»² (Solón 2019) ou «Homemtropoceno» ${ }^{3}$ (Raworth 2014) - que colocam o ónus da responsabilidade pela crise ecológica, respetivamente, na lógica do capital e do lucro, na concentração de poder nas mãos de uma elite, e na estrutura generizada do poder - nos parecem sociologicamente mais apropriados. Todas estas estruturas de poder estão eminentemente interseccionadas: não é possível compreendermos a concentração de poder e de riqueza nas mãos de uma elite sem relacionarmos essa dinâmica com o sistema capitalista financeirizado e com o sistema produtivista extrativista, que, por sua vez, assenta em lógicas de exploração da Natureza semelhantes à lógica de dominação patriarcal. Assim, neste artigo, sugerimos o conceito de "Antropoceno patriarcal», que permite reconhecer a interconexão entre as diferentes estruturas de opressão na génese da «Era dos Humanos» e que sublinha que as alterações climáticas têm consequências em termos de género, raça e classe, com especial incidência para as mulheres negras, pobres, do Sul Global, indígenas, campesinas, etc.

Nos países da OCDE, independentemente da classe, raça, etnia ou localização geográfica, as mulheres têm uma pegada ecológica inferior à dos homens. Contudo, a nível mundial, em caso de desastres naturais, as mulheres e crianças têm uma hipótese de morrer 14 vezes superior à dos homens (INWF 2015) e são elas as mais impactadas por fenómenos como as secas ou a escassez de comida, nomeadamente as do Sul Global (Goldsworthy 2010). Neste sentido, são as mulheres as maiores vítimas do capitalismo predatório, apesar de serem as que menos contribuem para o seu sistema de exploração e esgotamento de recursos. Também as populações indígenas sofrem desproporcionalmente os impactos das alterações climáticas, embora sejam as que mais esforços fazem por preservar o ambiente: apesar de constituírem apenas 5\% da população mundial, são responsáveis por proteger $80 \%$ da biodiversidade global (Raygorodetsky 2018). Ora, estas populações tendem a ser as mais impactadas pelos conflitos violentos despoletados por motivos ambientais e encontram-se em situações de pobreza superiores à média mundial, o que exacerba a sua vulnerabilidade (Baird 2008). Por fim, também as populações racializadas e outras minorias étnico-raciais, sistematicamente mais pobres, sentem de forma mais acutilante os efeitos das alterações climáticas. As populações negras dos EUA estão expostas a $56 \%$ mais poluição aérea do que a que é causada pelo seu consumo; nas populações latinas, este número eleva-se a 63\%; por seu turno, as populações brancas não-hispânicas estão sujeitas a menos 17\% de poluição aérea que a causada pelo seu consumo (Tessum et. al 2019).

O termo não deve ser confundido com o seu homólogo geológico que diz respeito a um possível período posterior ao «Antropoceno», em que os níveis de concentração de plutónio seriam tais que o Planeta Terra se tornaria um lugar inóspito.

3 Na versão original em inglês, a autora emprega a expressão «Manthropocene», um neologismo de difícil tradução para o português. 
Estas desigualdades refletem a estrutura desigual e injusta do atual sistema, onde múltiplos sistemas de opressão se combinam e se reforçam mutuamente. Em tempos de crise ecológica, esta análise permite entender que a justiça climática é (indissociável da) justiça social - de género, de raça, de classe socioeconómica. $\mathrm{Na}$ era do «Antropoceno patriarcal», quem sofre desproporcionalmente os efeitos das alterações climáticas são as mulheres, mas são também elas que se encontram na linha da frente da luta. É nesse sentido que as ativistas feministas ambientalistas têm vindo a ser permanentemente atacadas pelas estruturas de poder dominantes - sejam elas o Estado, os interesses paramilitares, as grandes indústrias extrativistas, ou ainda os líderes da ultradireita.

\section{Líderes políticos da ultradireita e crise climática: negacionismo climá- tico, petro-masculinidades, masculinidades industriais}

A crise climática convida-nos a repensar a nossa presença no Planeta, que sempre tivemos por infinita. Esta proximidade do fim coloca problemas existenciais ao modelo civilizatório atual, cuja expansão, crescimento e desenvolvimento assentam na exploração, sem fim e sem limites, dos recursos naturais e do trabalho reprodutivo, como explica o ecofeminismo. Ao ameaçar diretamente este sistema social, político e económico, a crise climática ameaça, consequentemente, quem historicamente mais beneficiou desta ordem. No contexto atual, os principais beneficiários da industrialização são os detentores dos meios de produção, os executivos destas indústrias, os gestores financeiros - na sua maioria, homens brancos ocidentais (Anshelm e Hultman 2015; Pulé e Hultman 2019b).

Os líderes políticos da ultradireita - na sua maioria homens com ligações fortes às indústrias do extrativismo fóssil (Sen 2019) - tendem a ser céticos ou até mesmo a negar as alterações climáticas antropogénicas (Anshelm e Hultman 2015; Pulé e Hultman 2019a e 2019b; Forchtner 2020). À semelhança de alguns/ /mas autores/as, argumentamos que as lutas feministas e ambientalistas, ao ameaçarem o business as usual e os privilégios individuais dessas elites, ameaçam a própria identidade masculina destes líderes e do seu eleitorado (Dunlap e McCright 2011 e 2015; Collomb 2014; Anshelm e Hultman 2015; Bell, Hulliger \& Brislen 2015; Daggett 2018; Greig 2019; Pulé e Hultman 2019b). Um estudo conduzido em 2011 revelou que o negacionismo climático dos homens brancos e conservadores estadunidenses funciona como uma forma de cognição, protetora da sua identidade masculina (Dunlap e McCright 2011). Um outro, levado a cabo em 2016 no Brasil e na Suécia, chegou às mesmas conclusões: os homens brancos conservadores têm mais tendência a negar as alterações climáticas, pois essa lógica discursiva ajuda à construção da sua identidade, historicamente orientada para a dominação (Jylhä et al. 2016). Estes estudos demonstram que, independentemente do contexto (geo)político e sociocultural, para os homens brancos e con- 
servadores - aqueles que mais tendem a lucrar com o sistema político-económico vigente -, o reconhecimento da emergência climática constitui uma ameaça direta à preservação de um status quo que lhes é benéfico - pois lhes confere lucros, privilégios e poderes - e que está inextricavelmente ligado às suas identidades masculinas, brancas e conservadoras (Dunlap e McCright 2011; Collomb 2014; Jylhä et al. 2016; Daggett 2018).

Ora, o «conservative male effect» (Jylhä et al. 2016) e o "white male effect» (Dunlap e McCright 2011) são particularmente notáveis em homens com tendência para votar na ultradireita contemporânea (Forchtner, Kroneder e Wetzel 2018; Mudde 2019; Norris e Inglehart 2019). Não é, pois, surpreendente que os líderes da ultradireita tendam a ser indiferentes, céticos ou até negacionistas das alterações climáticas (Anshelm e Hultman 2015; Dunlap e McCright 2015; Forchtner 2020). Reconhecer a necessidade de travar os processos de industrialização, assentes predominantemente no extrativismo fóssil, pilares do desenvolvimento e crescimento económico capitalista, implicaria admitir que a lógica político-económica neoliberal - que eles corroboram (Halimi e Rimbert 2016) - falhou profundamente. Ao invés de reavaliarem as suas bases intelectuais, estes líderes políticos adotam uma estratégia de negação, preservando assim a sua identidade político-intelectual (Collomb 2014) bem como a sua identidade masculina.

Perante a constatação das inegáveis ligações entre a emergência climática e as questões de género e de masculinidades, novos conceitos têm surgido na literatura. Anshelm e Hultman (2014) e Pulé e Hultman (2019a e 2019b) referem-se a masculinidades industriais e a breadwinner masculinities para salientar a aliança entre as identidades masculinas das elites industriais do Norte Global e as identidades dos trabalhadores da classe operária cujos empregos - e, consequentemente, a capacidade de desempenharem o seu papel de chefe de família (breadwinner) - têm até agora dependido da indústria de combustíveis fósseis. Como salienta Mutz (2018), o voto nas eleições de 2016 em Donald Trump explica-se, em parte, pela aliança entre estas duas identidades masculinas: no lado da oferta política, Trump apresenta-se enquanto acérrimo defensor da ordem industrial moderna e do extrativismo fóssil; no lado da procura política, encontramos homens brancos, de classe média-baixa, que sentem o seu estatuto de breadwinners ameaçado. Assim, este eleitorado vota numa personalidade cuja identidade é semelhante à sua e que, pelo menos em teoria, os protegerá das ameaças representadas pelas lutas progressistas (ibid.). Compreendemos, pois, que aquilo que estes grupos entendem como parte integrante do seu modo de vida - os privilégios e lucros, no caso das elites políticas industriais; a capacidade de manter o seu papel de género tradicional, no caso dos trabalhadores - é inseparável daquilo que entendem ser definidor da sua própria identidade masculina (Anshelm e Hultman 2014; Daggett 2018; e Pulé e Hultman 2019b).

O conceito de «petro-masculinidade», proposto por Cara Daggett, serve para «enfatizar a relação - tanto técnica quanto afetiva - entre os combustíveis fósseis e 
as ordens patriarcais brancas» (2018 28). De acordo com Daggett, quando analisamos a ascensão da ultradireita e nos debruçamos sobre os discursos oficiais dos seus líderes, importa estudar conjuntamente o discurso negacionista climático e o discurso misógino. Segundo a autora, o foco na «petro-masculinidade» permite reconhecer que a crise climática representa uma ameaça não só àquilo que tem sido o estilo de vida e o sistema económico favorecedor de determinados grupos de homens, mas também - igual e simultaneamente - uma ameaça às identidades masculinas, erigidas sobre esses estilos de vida e sobre o sistema patriarcal que os criou e sustenta. Este conceito sublinha ainda a forma como estes dois discursos se co-constituem para legitimar práticas autoritárias: a ordem industrial extrativista foi construída por e para homens brancos e as políticas autoritárias têm sido historicamente cruciais para garantir a segurança dessas ordens e privilégios. De facto, como sublinha a teoria ecofeminista, a ordem industrial extrativista requer um fluxo quase-infinito e barato de combustíveis fósseis e de trabalho doméstico não remunerado por forma a manter a concentração das riquezas nas mãos de uns em detrimento da precariedade, vulnerabilidade e pobreza de outro/as - o que só foi historicamente possível recorrendo a práticas autoritárias (Mies e Shiva 2014; Fraser 2017; Daggett 2018; Solón 2019).

No contexto de ascensão da ultradireita, estes (novos) conceitos ajudam-nos a compreender a forma como os líderes políticos da ultradireita reagem à crise climática reproduzindo padrões de masculinidade que contribuem para perpetuar a ordem vigente; e a forma como aprovam e apoiam medidas autoritárias e repressivas por forma a garantirem os interesses e privilégios da ordem industrial extrativista e da ordem patriarcal branca. Os exemplos dos discursos oficiais de Donald Trump e de Jair Bolsonaro no tocante à questão climática são particularmente ilustrativos da forma como os líderes políticos da ultradireita generificam a temática ambiental por forma a perpetuar o status quo do qual beneficiam.

$\mathrm{O}$ atual presidente brasileiro, por exemplo, recorre frequentemente à generificação do território amazónico e do/as habitantes da floresta. Ao retratar a Amazónia como um espaço por ocupar, dizendo que «Nossa Amazônia permanece praticamente intocada», Bolsonaro ativa imaginários patriarcais. Com efeito, as representações sociohistóricas do órgão sexual feminino fazem com que pensemos nele como um «buraco», como um orifício vazio a ser preenchido pelos homens (Mazaurette 2020). Ao dizer que a Amazónia é «uma virgem que todo o tarado de fora quer $»^{4}$, Bolsonaro ativa esses imaginários patriarcais, representando este território como passivo, à espera de ser ocupado, explorado, preenchido. Analisada na perspetiva ecofeminista, a Amazónia, tal como os corpos das mulheres ao longo da história, é representada como passiva, submissa, um espaço de disponibilidade para a exploração do "patriarcado capitalista». Bolsonaro representa

Citado no Observador (10 de agosto de 2020). Disponível em: https: / / observador.pt/ 2020 / 08 / 10 / ministerio-publico-do-brasil-acusa-bolsonaro-e-ministros-brasileiros-por-ofensas-a-mulheres / 
ainda as populações que habitam a floresta e/ou que a protegem como «inferiores», «selvagens», «incultas» - categorias associadas historicamente ao género feminino. Repetidas vezes, Bolsonaro lamenta que o seu país não esteja «nas mãos de israelense, sul-coreanos, japoneses», pois, se estivesse, tudo «seria diferente». Bolsonaro opõe essas populações ocidentais às populações negras, indígenas e pobres, que são definidas como «selvagens», «corpóreas», «inferiores» nos seus discursos. $\mathrm{O}$ atual Presidente chegou a comparar negros a gado, ao dizer que «O afrodescendente mais leve lá [num quilombo] pesava sete arrobas». Ao retratar assim as populações da floresta e o próprio território amazónico, Bolsonaro legitima práticas autoritárias de extração de recursos, de não-demarcação de terras indígenas, de parcerias com o capital e investimento estrangeiro, de megaprojetos industriais. Isto é, justifica práticas autoritárias que permitem consolidar e proteger a ordem vigente, que beneficia as identidades masculinas (industriais e petro[líferas]), serve os interesses do «patriarcado capitalista», justifica comportamentos ecologicamente irresponsáveis, contribuindo, assim, para a patriarcalização do Antropoceno.

Também o anterior presidente estadunidense, Donald Trump, se serviu do negacionismo climático para captar eleitorado masculino e para perpetuar a ordem vigente, da qual sempre beneficiou. De acordo com Mutz (2018), as eleições estadunidenses de 2016 explicam-se sobretudo por questões culturais e identitárias e não tanto por perdas económicas. Um dos discursos que Trump mais mobilizou foi a tese segundo a qual os EUA estariam a perder estatuto por conta da ascensão global da China, e Mutz estuda particularmente como este discurso mobilizou uma grande parte do eleitorado masculino cuja identidade depende de se conceber como cidadão de uma nação poderosa. No caso da questão climática, é interessante notar como Trump combina o discurso anti-China e de reforço da dominação estadunidense com o discurso anti-climático e de reforço da dominação extrativista, apelando, assim, aos WASP (White, Anglo-Saxon, Protestant, and Male). Por exemplo, em novembro de 2012, Trump tweetou que «O conceito de aquecimento global foi criado por e para os chineses com a finalidade de tornarem a indústria manufatureira dos EUA não-competitiva». Mal foi eleito presidente, Trump retirou os EUA do Acordo de Paris e passou legislação favorável à indústria fóssil, com quem tem relações muito próximas (CAP Action 2019). O seu negacionismo climático permitiu, deste modo, perpetuar o status quo e aprovar medidas autoritárias e repressivas de destruição ecológica.

Em suma, os conceitos de «masculinidades industriais» e de «petro-masculinidade» sugerem que os combustíveis fósseis têm um significado para além do lucro: eles moldam e contribuem para a formação de identidades sociais, nomeadamente das identidades masculinas - no caso do eleitorado de Trump, a identidade dos WASPs; no caso do eleitorado de Jair Messias Bolsonaro, a identidade dos fazendeiros, dos detentores da propriedade privada, do agronegócio. É neste sentido que podemos afirmar que os líderes da ultradireita, nos seus discursos, (re) 
produzem padrões de masculinidade que servem a proteção da ordem vigente, que lhes é benéfica e da qual não querem abdicar, e que contribuem para legitimar práticas autoritárias e ecologicamente irresponsáveis.

\section{Conclusão}

Neste artigo, partindo do contexto de crise climática, procurámos refletir sobre a forma como esta emergência não pode ser analisada sem a relacionarmos com as estruturas de opressão, nomeadamente as patriarcais. Embora os estudos sobre masculinidades e a crise climática sejam ainda periféricos, este ângulo permite-nos tecer uma análise mais criticamente detalhada sobre as implicações da crise climática em termos de género, classe e raça.

$\mathrm{Na}$ era do Antropoceno patriarcal, e face à explosão das lutas feministas e ambientalistas, os líderes políticos da ultradireita persistem em negar ou em ignorar o problema. Uma análise (eco)feminista do negacionismo climático permite-nos entender a forma como este discurso das elites dominantes - na sua maioria masculinas - serve não só a proteção, preservação e manutenção da odem vigente, que lhes é benéfica, como também a proteção das suas próprias identidades masculinas. É neste sentido que estes líderes (re)produzem padrões de masculinidade - de cariz autoritário - que servem os interesses da ordem extrativista bem como da ordem patriarcal, que historicamente sustentou a primeira. Esta proposta teórica foi ilustrada por exemplos concretos, nomeadamente dos discursos de Donald Trump e de Jair Messias Bolsonaro, que demonstram a forma como estes chefes de Estado procedem à generificação da temática ambiental para justificar e legitimar práticas autoritárias em favor do «patriarcado capitalista».

Hoje, vivemos momentos de destruição socioecológica acelerada acompanhados da ascensão de governos antidemocráticos. Para enfrentar estas crises, será necessária uma transformação multidimensional, que passa também pela desconstrução das normas de género dominantes. Assim, e como sugerem Bell e Braun (2010) e Pulé e Hultman (2019a), os estudos sobre masculinidades devem procurar envolver homens nos movimentos ambientais. O combate ao Antropoceno patriarcal começa pela construção de masculinidades ecologicamente mais conscientes, responsáveis e cuidadoras.

\section{Referências bibliográficas}

Anshelm, Jonas, e Martin Hultman. 2015. Discourses of Global Climate Change. Apocalyptic framing and political antagonisms. London: Routledge.

Anshelm, Jonas, e Martin Hultman. 2014. «A green fatwa? Climate change as a threat to masculinity of industrial modernity.» NORMA: International Journal for Masculinity Studies 9(2): 84-96. DOI: https: / / doi.org/10.1080/18902138.2014.908627 
Appadurai, Arjun. 2009. O medo ao pequeno número: ensaio sobre a geografia da raiva. São Paulo: Editora Iluminuras.

Arruzza, Cinzia, Tithi Bhattacharya, e Nancy Fraser. 2019. Feminism for the 99\%: A Manifesto. London: Verso Books.

Baird, Rachel. 2008. The Impact of Climate Change on Minorities and Indigenous Peoples. London: Minority Rights Group International.

Bell, Shannon Elizabeth, e Yvonne A. Braun. 2010. «Coal, identity, and the gendering of environmental justice activism in central Appalachia.» Gender \& Society 24(6): 794-813. DOI: https:/ / doi.org/10.1177/0891243210387277

Bell, Shannon Elizabeth, Alicia Hullinger e Lilian Brislen. 2015. «Manipulated Masculinities: Agribusiness, Deskilling, and the Rise of the Businessman-Farmer in the United States.» Rural Sociology 80(3): 285-313. DOI: https: / / doi.org/10.1111/ ruso.12066

Bello, Walden. 2019. Counterrevolution: The Global Rise of the Far Right. Nova Scotia: Fernwood Publishing.

Boddice, Rob. 2011. Anthropocentrism. Humans, Animals, Environments. Leiden: Brill.

Bringel, Breno, e Geoffrey Pleyers. 2017. Protesta e Indignación Global. Los movimientos sociales en el nuevo orden internacional. Buenos Aires: CLACSO.

CAP Action. 2019. «Here's Everything You Need to Know About Trump's Fossil Fuel Connections.» Disponível em https://capaction.medium.com/heres-everythingyou-need-to-know-about-trump-s-fossil-fuel-mafia-54eda20f4a8b [Consultado a 21 de março de 2021].

Climate Accountability Institute. 2017. The Carbon Majors Database CDP Carbon Majors Report 2017. Colorado: CDP.

Collomb, Jean-Daniel. 2014. «The Ideology of Climate Change Denial in the United States.» European Journal of American Studies 9-1. DOI: https: / / doi.org/10.4000/ ejas.10305

Connell, Raewyn. 1993. Masculinities. Berkeley: University of California Press.

Crutzen, Paul, e Eugene Stoermer. 2000. «The 'Anthropocene'.» Global Change Newsletter 41: 17-18.

Daggett, Cara. 2018. «Petro-masculinity: Fossil Fuels and Authoritarian Desire.» Millennium: Journal of International Studies 47(1): 25-44. DOI: https:/ / doi.org/10.1177/ 030582981 8775817

Dardot, Pierre, e Christian Laval. 2019. «Anatomie du nouveau néolibéralisme.» Disponível em http: / / reflexions-echanges-insoumis.org/anatomie-du-nouveau-neoliberalisme / [Consultado a 10 de agosto de 2020].

Dunlap, Riley, e Aaron McCright. 2011. «Cool dudes: The denial of climate change among conservative white males in the United States.» Global Environmental Change 21(4): 1163-1172. DOI: 10.1016/j.gloenvcha.2011.06.003

. 2015. «Challenging Climate Change: The Denial Countermovement.» In Climate Change and Society: Sociological Perspectives, editado por Riley Dunlap e R.J. Brulle, 300332. New York: Oxford University Press.

Elias, Norbert. 1991. The Symbol Theory. London: Sage.

Federici, Silvia. 2019. Calibã e a Bruxa. Mulheres, corpo e acumulação primitiva. São Paulo: Editora Elefante.

Forchtner, Bernhard, Andreas Kroneder, e David Wetzel. 2018. «Being Skeptical? Exploring Far-Right Climate-Change Communication in Germany.» Environmental Communication 12(5): 589-60. DOI: $10.1080 / 17524032.2018 .1470546$

Forchtner, Bernhard. 2020. The Far Right and the Environment. Politics, Discourse and Communication. Abingdon: Routledge. 
Foster, John. 1977. Class Struggle and the Industrial Revolution. Early Industrial Capitalism in Three English Towns. London: Routledge.

Fraser, Nancy. 2017. Social Reproduction Theory: Remapping Class, Recentering Oppression. London: Pluto Press.

Gaard, Greta. 1993. Ecofeminism. Women, Animals, Nature. Philadelphia: Temple University Press.

Giddens, Anthony. 2007. Beyond Left and Right. Cambridge: Polity Press.

Goldsworthy, Heather. 2010. «Women, global environmental change and human security.» In Global Environmental Change and Human Security, editado por Richard A. Matthew et al., 215-235. Cambridge: MIT Press.

Grassby, Richard. 1999. The Idea of Capitalism before the Industrial Revolution. Maryland: Rowman \& Littlefield Publishers.

Greig, Alan. 2019. «Masculinities and the Rise of the Far-Right. Implications for Oxfam's Work on Gender Justice.» Oxfam Research Backgrounder series. Disponível em https:/ / www.oxfamamerica.org/explore/ research-publications / masculinities-and-the-farright/ [Consultado a 21 de agosto de 2020].

Halimi, Serge, e Pierre Rimbert. 2019. «Assim surgiu o proto-fascismo contemporâneo.» Disponível em https: / / outraspalavras.net/direita-assanhada/assim-surgiu-o-proto fascismo-contemporaneo/ [Consultado a 4 de outubro de 2019].

Herrero, Yayo, e Marta Pascual. 2010. «Ecofeminismo, una propuesta para repensar el presente y transitar al futuro.» Boletín ECOS 10: 1-9.

Herrero, Yayo. 2013. «Miradas ecofeministas para transitar a un mundo justo y sostenible.» Revista de Economía Critica 16: 278-307.

Hibbs, Carolyn. 2014. «Androcentrism». In Encyclopedia of Critical Psychology, editado por Thomas Teo. New York: Springer.

INWF. 2015. Climate Justice and Women's Rights: A guide to supporting grassroots women's actions. London: Global Greengrants Fund.

Jylhä, Kirsti M. et al. 2016. «Denial of anthropogenic climate change: Social dominance orientation helps explain the conservative male effect in Brazil and Sweden.» Personality and Individual Differences 98: 184-187. DOI: 10.1016/j.paid.2016.04.020

Mazaurette, Maïa. 2020. Sortir du trou ! Lever la tête. Paris: Anne Carrière Editions.

Mies, Maria, e Vandana Shiva. 2014. Ecofeminism. London: Zed Books.

Moore, Jason. 2016. Anthropocene or Capitalocene? Nature, History and the Crisis of Capitalism. Oakland: PM Press.

Mudde, Cas. 2019. The Far Right Today. Cambridge: Polity Press.

Mutz, Diana. 2018. «Status threat, not economic hardship, explains the 2016 presidential vote.» PNAS 115(9). DOI: https:/ / doi.org/10.1073/pnas.1718155115

Norris, Pippa e Ronald Inglehart. 2019. Cultural Backlash: Trump, Brexit, and Authoritarian Populism. Cambridge: Cambridge University Press.

OXFAM. 2015. «World's richest $10 \%$ produce half of carbon emissions while poorest 3.5 billion account for just a tenth.» Disponível em https://www.oxfam.org/en/pressreleases / worlds-richest-10-produce-half-carbon-emissions-while-poorest-35-billionaccount [Consultado a 10 de maio de 2020].

OXFAM. 2017. «Uma Economia para os 99\%.» Disponível em https: / / oxfam.org.br/justicasocial-e-economica / forum-economico-de-davos / uma-economia-para-os-99/ [Consultado a 10 de outubro de 2019].

Paterson, Matthew. 2005. «Green Politics.» In Theories of International Relations, editado por Scott Burchill et al., 235-257. New York: Palgrave Macmillan. 
Pellizzoni, Luigi. 2019. «Climate crisis and new ecological mobilisations (Part I).» Disponível em https: / / undisciplinedenvironments.org/2019/11/08/ climate-crisis-and-newecological-mobilisations-part-i/ [Consultado a 1 de junho de 2020].

Pulé, Paul, e Martin Hultman. 2019a. Ecological Masculinities. Theoretical Foundations and Practical Guidance. Abingdon: Routledge.

Pulé, Paul, e Martin Hultman. 2019b. «Industrial / Breadwinner Masculinities and Climate 4 Change: Understanding the 'White Male Effect' of Climate Change Denial.» In Climate Hazards, Disasters, and Gender Ramifications, editado por Helle Rydström e Catarina Kinnvall, 86-100. Abingdon: Routledge.

Raworth, Kate. 2014. «Must the Anthropocene be a Manthropocene?» Disponível em https: / / www.theguardian.com / commentisfree / 2014 / oct/ 20 / anthropoceneworking-group-science-gender-bias [Consultado a 11 de junho de 2019].

Raygorodetsky, Gleb. 2018. «Indigenous people defend the Earth's biodiversity - but they're in danger.» Disponível em https://www.nationalgeographic.com/environment/ 2018/11 / can-indigenous-land-stewardship-protect-biodiversity-/ [Consultado a 9 de maio de 2020].

Santos, Boaventura de Sousa. 2007. «Para além do pensamento abissal: das linhas globais a uma ecologia de saberes.» Novos estudos CEBRAP 79: 71-94. DOI: http://dx.doi. org/10.1590/S0101-33002007000300004

Sen, Basav. 2019. «Dig Beneath the World's Far-Right Governments - You'll Find Fossil Fuels.» Disponível em https://ips-dc.org/dig-beneath-the-worlds-far-rightgovernments-youll-find-fossil-fuels/ [Consultado a 26 de agosto de 2020].

Solón, Pablo. 2019. «Introdução». In Alternativas Sistêmicas: Bem Viver, decrescimento, comuns, ecofeminismo, direitos da Mãe Terra e desglobalização, organizado por Pablo Solón, 13-17. São Paulo: Editora Elefante.

Tessum, Christopher et al. 2019. «Inequity in consumption of goods and services adds to racial-ethnic disparities in air pollution exposure.» PNAS 116(13): 6001-6006. DOI: https: / / doi.org/10.1073/ pnas.1818859116

Walby, Sylvia. 1989. «Theorising Patriarchy.» Sociology 23(2): 213-234.

Wodak, Ruth. 2015. The Politics of Fear. What Right-Wing Discourses Mean. London: SAGE Publications.

Mariana Riquito. Investigadora Júnior no Centro de Estudos Sociais da Universidade de Coimbra (CES/UC); Pesquisadora Internacional do LABMUNDO - Laboratório de Análise Mundial, do Instituto de Estudos Políticos e Sociais da Universidade do Estado do Rio de Janeiro (IESP/UERJ); Licenciada e Mestre em Relações Internacionais pela Faculdade de Economia da Universidade de Coimbra (FEUC); Bacharel em Estudos Políticos e Mestre em Sociologia e Ciência Política pelo Instituto de Estudos Políticos de Bordéus (IEP).

Endereço eletrónico: mariana.riquito@gmail.com / marianariquito@ces.uc.pt

Artigo recebido a 04 de janeiro e aceite para publicação a 21 de março de 2021. 
